\title{
DYNAMICAL SIMULATION OF A VALVETRAIN MECHANISM: AN ENGINEERING EDUCATION APPROACH
}

\begin{abstract}
M. A. A. Nunes,
R. C. Silva,

A. B. S. Oliveira,

and G. C. Peron

Universidade de Brasília

Faculdade UnB Gama/ Engenharia Automotiva

Área Especial de Indústria Projeção A,

Setor Leste, CEP: 72.444-240

Gama-DF, Brasil

maanunes@unb.br

ritasilva@unb.br

abso@unb.br

caetanoperon@gmail.com

Received: November 23, 2012

Revised: December 23, 2012

Accepted: January 24, 2013

ABSTRACT

The present work aims to present a valvetrain model considering the dynamics functioning aspects of an Otto's engine. The model will be constructed using Adams/View ${ }^{\circledR}$ software, which is a powerful modeling and simulating environment of dynamic systems. It allows building, simulating, refining and optimizing any mechanical system. In fact, the model will help engineering students to understand how the mechanism works, in terms of displacement, velocity and acceleration of the valve as a function of the time. It is also possible to know the behavior of the force in the spring as a function of the time and, finally, the torque applied in the cam due to a angular velocity input. Relative to spring force, during the Otto engine cycle, the cam lobe must be able to open and close the valve as fast and as smoothly as possible. The force responsible to close the valve is applied by the valve spring, which is also responsible for keeping contact between the cam lobe and the valve. Dynamic forces impose limits on cam and valve lift. Thus, the simulation model allows determining these forces and displacements through the cam rotation. As main objectives the authors wish to make available a model which is capable to show in 3D the animation of a valvetrain mechanism of an Otto engine, obtaining the main curves for analysis and evaluation of this mechanism performance.

Keywords: valvetrain, cam, multibody, Adams/View ${ }^{\circledR}$, Otto’s engine
\end{abstract}

\section{INTRODUCTION}

The petrol or oil engine is a form of internal combustion 'heat engine', which the main function is to convert potential heat energy contained in the fuel into mechanical work. Also, it represents the source of power with which the society is immediately concerned.

The dawn of the motor vehicle age occurred around 1769 when the french military engineer, Nicholas Joseph Cugnot (1725-1804), built a threewheeled, steam-driven vehicle for the purpose of pulling artillery pieces. In 1784 a steam-powered vehicle was built by the Scottish engineer, James Watt (1736-1819), which proved unworkable. By 1802, Richard Trevithick (1771-1833), an Englishman, developed a steam coach that traveled from Cornwall to London (Gillespie, 1992).

The first engine to come into general use was built by Lenoir in 1860. The engine resembled a single-cylinder, double-acting horizontal steam engine, with two power strokes per revolution. The next significant step was the Otto and Langen atmospheric or free-piston engine of 1866; the fuel consumption was about half that of the Lenoir engine. The main features of the engine were a long vertical cylinder, a heavy piston and a racked piston rod (Stone, 1999).

At the same time commercial exploitation of oil wells in the USA was occurring, as a result of the pioneer drilling by Drake in 1859. This led to the availability of liquid fuels that were much more convenient to use than gaseous fuels. Liquid fuels without doubt accelerated the development of internal combustion engines. In 1876 the Otto silent engine using the four-stroke cycle was patented and then produced. As well as being much quieter than the free-piston engine, the silent engine was about three times as efficient. Immediately following the Otto silent engine, two-stroke engines were developed. Patents by Robson in 1877 and 1879 and Clerk in 1878 and 1881 describe the two-stroke cycle under different functioning conditions (Stone, 1999).

The first practical automobiles powered by gasoline engines arrived in 1886 with credit generally going to Karl Benz (1844-1929) and Gottlieb Daimler (1834-1900), Otto and Langen's partner (Gillespie, 1992). Over the next decade, automotive vehicles were developed by many other pioneers with familiar names such as Rene Panhard, Emile Levassor, Armand Peugeot, Frank and Charles Duryea, Henry Ford and Ransom Olds. In Europe the familiar companies like Daimler, Opel, Renault, Benz and Peugeot were becoming recognized as automotive manufacturers.

Thus accordingly to history one type of internal combustion engine is the spark ignition engines, also called Otto engine, where the fuel is ignited by a spark. Another possible type is the compression ignition engines, where the rise in temperature and pressure during compression is sufficient to cause spontaneous ignition of the fuel. 
During each crankshaft revolution there are two strokes of the piston, and both types of engine can be designed to operate in either four or two strokes of the piston.

The four stroke operating cycle can be defined as: induction, compression, expansion and exhaust strokes. Each stroke refers to the movement of the piston. In the induction stroke, the inlet valve is open, the air enters and fuel is usually pre-mixed with the air. In the compression stroke valves are closed and piston travels up the cylinder. As it approaches to top dead centre, ignition occurs. In the expansion, combustion propagates throughout the charge, raising the pressure and temperature, and forcing the piston down. At the end of the power stroke the exhaust valve opens, and irreversible expansion of the exhaust gases is termed. In the last phase, the exhaust valve remains open to expel gases.

Depending on the engine architecture, it has a valve set that allows induction and exhaust, cams, camshafts operating via cam follower, push rods and rocker arm. This mechanism is known as valvetrain and it is responsible for the internal combustion engine functioning (Heisler, 2008).

This way, the present work aims to present this mechanism involving a valve-operating system with overhead poppet valves (OHV - overhead valves), where the camshaft is either mounted in the cylinder block. The proposed model is simple and it will allow engineering students understanding dynamics aspects of this mechanism. Model will be constructed using Adams/View (MSC Software) that is a powerful modeling and simulating environment that allows building and simulating any mechanical system. In fact, the model permits the analysis of displacement, velocity and acceleration of the valve versus time, the force in the spring versus time, and also, the torque in the cam.

\section{VALVETRAIN MECHANISM}

Since the conception of the automobile, the internal combustion engine has evolved considerably, but one aspect has remained throughout engine development. The camshaft has been the primary means of controlling the valve actuation and timing. The valvetrain mechanism, in its simplest form, consists on a camshaft via cam followers, springs, valves and mechanical linkage (push rod and rocker arms) (Bosch, 2007 and Stone, 1999). During the mechanism functioning, as the camshaft rotates, cam lobes, attached to the camshaft, interface with engine's valves. This interface may take place via mechanical linkage and, as the cam rotates, it forces the valve to open. The spring return and it closes the valve, when the cam is no longer supplying the opening force (Brader, 2001).

Since the timing of the engine is dependent on the shape of the cam lobes and the rotational velocity of the camshaft, engineers must make decisions early in the automobile development process that affect the engine's performance (Taraza et al., 1999; Brader, 2001). This fact points to the importance of understand the dynamic functioning and design influence of such a mechanism.

Basically, there are four valve-timing concepts as shown in Fig. 1. According to the design, the drive system, which opens the valves, has four different configurations. Figure 1.1 represents a push-rod assembly, where the camshaft is placed laterally to the cylinder head. In this mechanism, a bucket moving back and forth in the cylinder head absorbs the cam lobe's lateral force, while transferring its linear actuating pressure to the valve stem. Others designs refer to OHC and DOHC, but in this work, it will be simulated an OHV design (push-rod assembly) (Bosch, 2007).
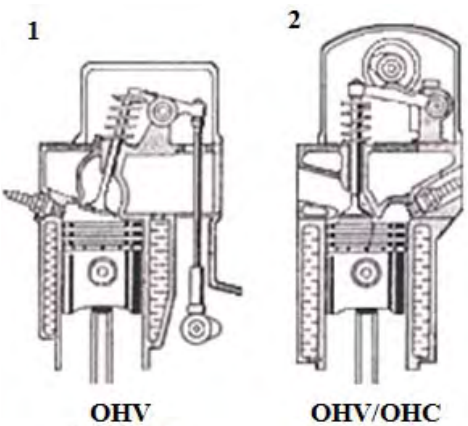

Push-rod assembly

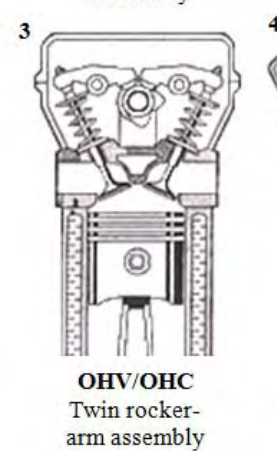

OHV/OHC

Single rockerarm assembly

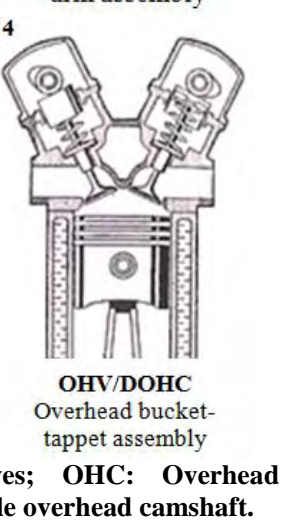

OHV: Overhead valves; OHC: Overhea

Figure 1. Valvetrain Models (Source: Bosch, 2007).

Taraza et al. (1999) mentioned that a push-rod assembly is largely employed in diesel engines. Although to reduce the number of gears necessary to put into motion the camshaft, this kind of construction add mass in the construction linkage; hence it can cause high vibrations and, consequently, high levels of noise. Figure 2 highlights this mechanism.

The most commonly used valve among valvetrain types is the mushroom-shaped poppet valve. It has the advantage of being cheap, with good flow properties, good seating, easy greasing and good heat transfer to the cylinder head as mentioned by Stone (1999) and Heisler (2008). 
The rocker arm in a push rod assembly supports the push rod in one side and the spring/valve in the other one, as shown in Fig. 3. Its function is to transmit the push rod movement to allow valve opening. In the center, the rocker arm has a hole to incase itself in the set axle. Figure 4 shows rocker arm mounted in the Otto engine.

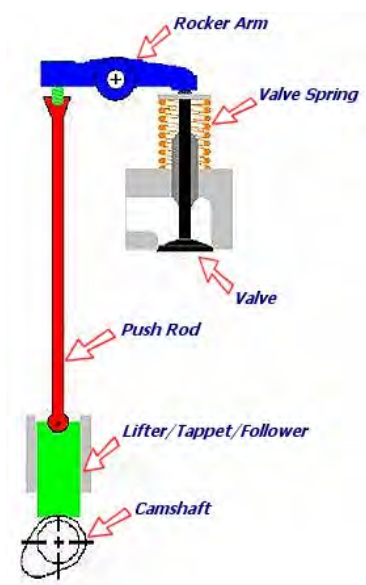

Figure 2. Push-rod.

The valve's spring has the length and the stress adapted according to the engine. In fact, the spring retains the valve in order to keep air entrance close, whenever the rocker arm is not pressuring the set.

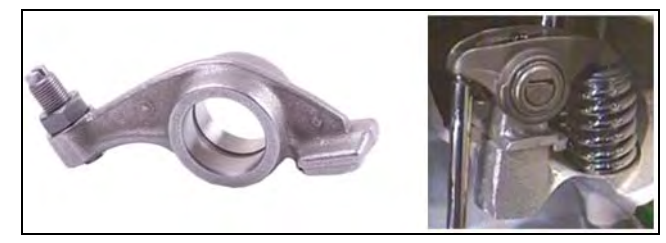

Figure 3. Rocker arm.

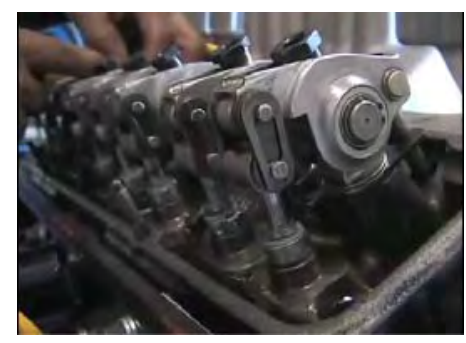

Figure 4. Rocker arm mounted in the motor.

The valve's spring has the length and the stress adapted according to the engine. In fact, the spring retains the valve in order to keep air entrance close, whenever the rocker arm is not pressuring the set.

\section{PROPOSED METHODOLOGY APPLIED IN THE MODEL DEVELOPMENT}

In this section, the authors present the main actions to construct a simple multibody model capable to simulate the valvetrain mechanism in the Adams/View ${ }^{\circledR}$ Software.

A brief description of the proposed model: the cam is being rotated at a given velocity and the rod (follower) moves in translational direction based on its constraint to the cam. The rocker pivots about a pin attached to the engine block and the spring is always in compression to try and keep the rod in contact with the cam. The valve moves vertically as the rocker rotates. When the valve moves, it lets small amounts of air into the chamber below it (not modeled here).

The geometrical dimensions were obtained from an original and real system from a common vehicle. Precision metrological equipments were used in this step, like caliper, micrometer, etc.

From the measured geometrical data, and due to the model be a simple mechanism, it was design directly in the Adams/View ${ }^{\circledR}$ Software. In Fig. 5, it is shown the designed model and in the table below it is shown the part names with the software tool used to build each one. As it just said it represents an OHV engine design (illustrated in Fig. 2).

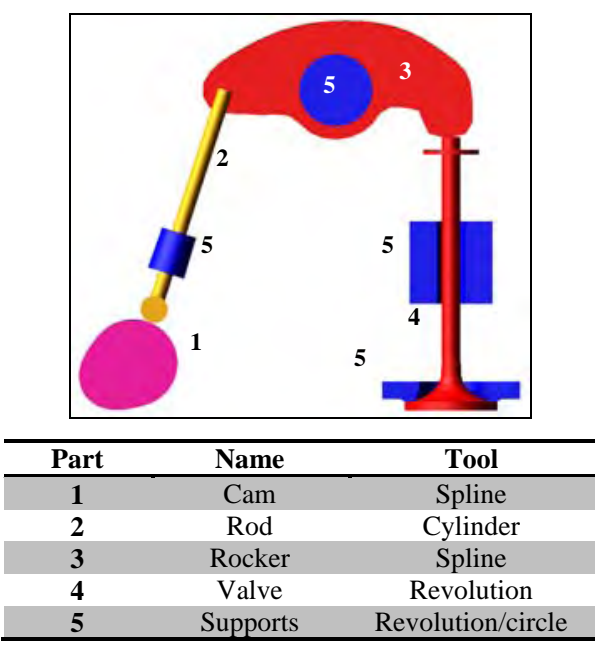

Figure 5. Multibody model developed in Adams/View ${ }^{\circledR}$ Software.

As seen in the table of the Fig. 5, some parts of the model require the use of specific tools of the software, like spline, cylinder and revolution, which are no trivial tools.

The spline was used for the construction of the rocker and cam. This tool requires previous information of some points, which compose the surface formed by it. The part (cam or rocker) is created selecting these points, and the software is capable to interpolate them creating the complete surface.

The cam model used in this work is shown in Fig. 6.a. The length from the nose to circle center is $0.08 \mathrm{~m}$. The radius of the base circle is $0.035 \mathrm{~m}$ and the lobe lift is $0.03 \mathrm{~m}$. The Figure 6.b illustrates the spline toolbox used to insert the points necessary to 
design the cam surface. The same process is used to design the rocker part.

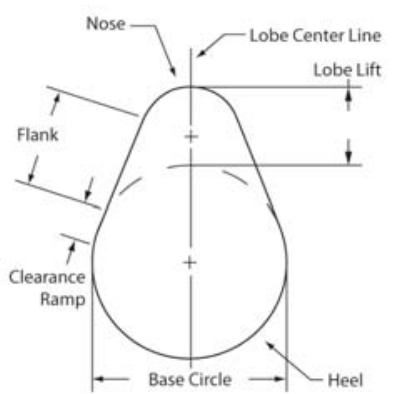

(a)

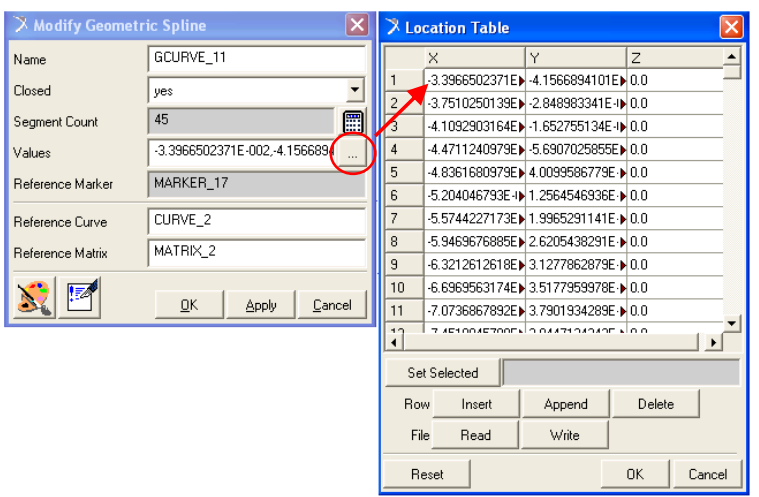

(b)

Figure 6. a) Cam geometry; b) Spline toolbox of Adams/View ${ }^{\circledR}$.

The cylinder tool was used to build the rod as shown in Fig. 5 (identified by number 2). This tool requires the radius and the length of the cylinder. In this model, the length is $0.19 \mathrm{~m}$ and the radius is 0.01 $\mathrm{m}$. The toolboxes used to design this part are shown in Fig. 7.

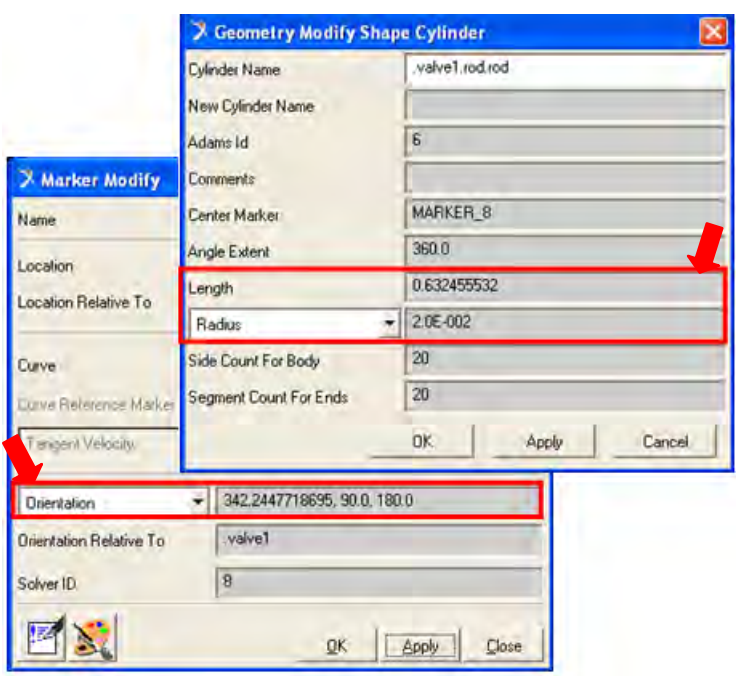

Figure 7. Cylinder geometry (above) and rod orientation/inclination (bellow).
Figure 7 shows the toolbox used to define the cylinder geometry and the toolbox used to inform the orientation of the rod (inclination), as seen in Fig. 5 (part number 2). The inclination modification is done changing the orientation of the center marker (this is a kind of local referential of the part) of the cylinder.

The revolution tool was used to design the valve part (part number 4 in the Fig. 5) and the supports (part number 5 in the Fig. 5) of the valvetrain mechanism. Before use this tool it is necessary design a "generator" of each part of interest, using the polyline tool (as illustrated in the Fig. 8.a).

The revolution tool rotates each "generator" around a defined axis. In Fig. 8.a is shown two "generators" which is the support for the valve. In order to obtain the solid (volume) parts as shown in Fig. 5 it is necessary to define the angle extent as $180^{\circ}$, as illustrated in Fig. 8.b.

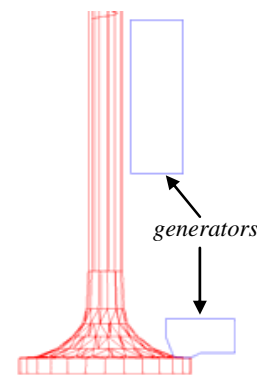

(a)

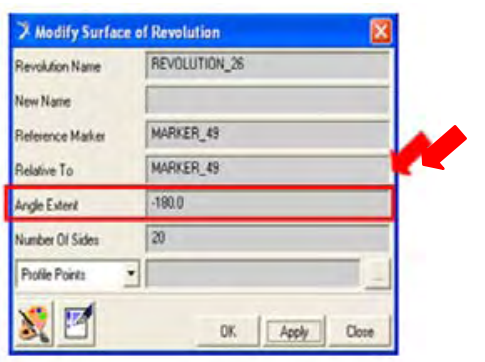

(b)
Figure 8. a) "Generators” used to design the valve supports; b) Angle extent of the supports.

After design the geometrical parts of the model, it is necessary to define the joints of the mechanism, which will define the movement limits and the degree of freedom of the system. In this model were modeled seven joints: two revolute joints, one translational joint and four primitive joint.

The revolute joints were used to define rotation (center axis of the cam and rocker) in the cam and rocker parts. Specifically in the revolute joint of the cam part, it was imposed a constant angular velocity of $6.28 \mathrm{rad} / \mathrm{s}$.

A translational joint was applied in the valve, which restricts this part to up and down displacement.

The primitive joints were applied in the rod (two units) and in the rocker (two units). Two of these joints establish the link of these two parts, and the other two joints make the connection of the rocker and valve.

In the valve part was necessary to create a spring-damper mechanism. The stiffness coefficient was $1271.5 \mathrm{~N} / \mathrm{m}$ and a damper coefficient is request by the software. In this case a little damper coefficient was used: $1.3 \mathrm{~N}$.s $/ \mathrm{m}$. The spring attached to the valve guarantees its return to the initial position, allowing the valve closure. So, it is necessary to add a pre-load in this system (springdamper) to ensure a correct dynamic simulation. This 
step approximates the virtual model to the real model and eliminates noises interferences in the simulated results. The imposed pre-load was $445 \mathrm{~N}$.

The completed model obtained in the Adams/View ${ }^{\circledR}$ Software is illustrated in Fig. 9.

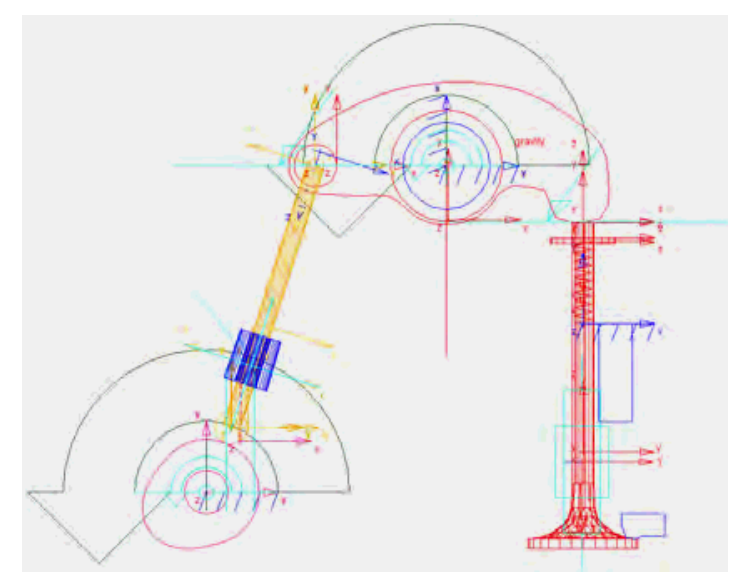

Figure 9. Complete multibody model of the valvetrain mechanism.

After the mechanism completely designed, the next step is to perform the dynamic simulation. In this stage, it is possible to obtain important results as the kinematics parameters and the internal forces between the parts of interest. For didactic application, the computational results obtained from the virtual model can be compared with theoretical results, commonly available in the literature of the thermal area.

The software let the user to view the motion of the complete system, as well as to modify the dynamic of the model. It can be done by varying the main parameters of the mechanism, like inputs data and geometry.

The simulation step was performed from the toolbox "interactive simulation controls", which is located in the Main Toolbox of the software. Figure 10 shows the simulation parameters: End Time $=5.0$ seconds and Steps $=500$.

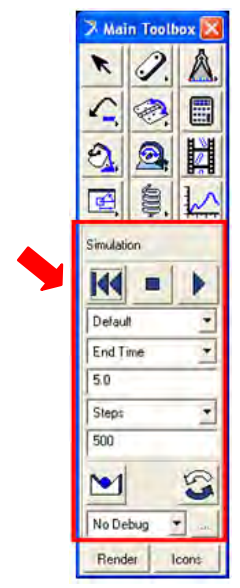

Figure 10. Simulation parameters.
If desired, the geometrical model designed in the Adams/View can be exported to CAD (Computer Aided Design) software. With the CAD model the user can easily make geometry changes. Also the appearance of the mechanism drawing becomes better. In this work the CAD software used was the CATIA $^{\circledR}$ V6 which is a multi-platform CAD/CAM/CAE developed by Dassault Systémes. The export data operation is shown in the Fig. 11.

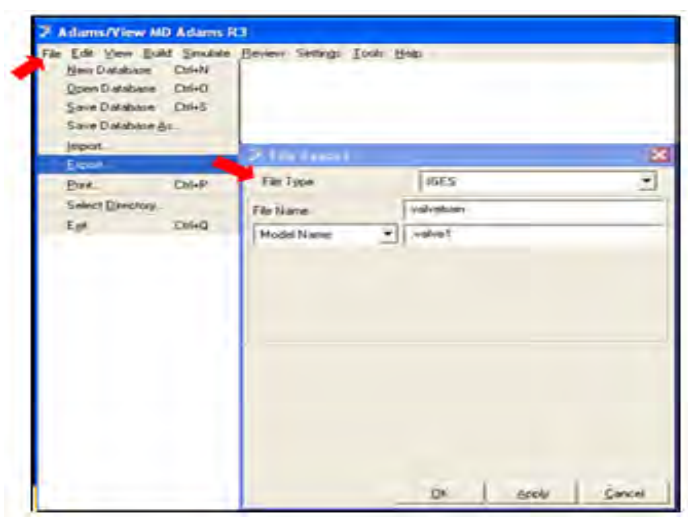

Figure 11. Export data operation.

Figure 12 shows the resulting model in the CATIA interface. It can be noticed that the feature of the mechanism is better than that obtained in the multibody software as shown in Fig. 5 and Fig. 9.

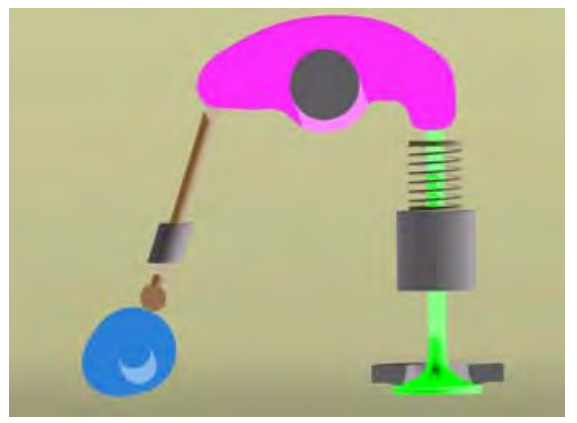

Figure 12. Model in the CATIA ${ }^{\circledR}$ software.

\section{RESULTS}

This section presents the main results obtained from the kinematic and dynamic model simulation. It is important to notice that only basic results were achieved for the chosen valvetrain (Fig. 1.1) in order to show the multibody model potentiality. In general, the main literature in this area presents these results to the student.

Figure 13 illustrates the torque measured in cam's rotation axis and the translational displacement of the valve's center of mass. These results are important to designers, because they can evaluate cam's behavior according to a defined displacement in the valve. 


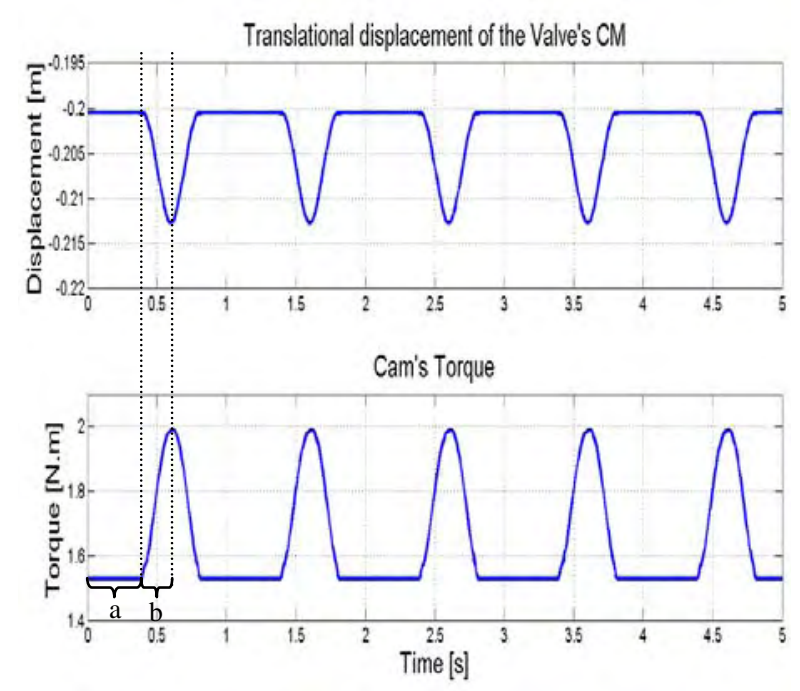

Figure 13. Torque in the cam and displacement of the valve.

Analyzing the torque's curve (continuous line) in the Fig. 13 we can observe that in the time interval 0 to 0.39 seconds (indicated by letter ' $a$ ' in the horizontal axis) the torque is constant. This means that the push rod is in contact with the base circle of the cam (like indicated in Fig. 6.a). During this time, a considerable amount of torque is required to extrapolate the contact force between the cam and the rod. In this same interval of time, the valve's displacement is null, because no motion is transmitted from the cam to the rest of the mechanism.

Between the interval of time 0.4 and 0.62 seconds (indicated by letter ' $b$ ' in the horizontal axis), the cam applies a greater force in the push rod overcoming the contact force between both. This is acquired in the contact of the rod with the cam in the flank zone until its nose (as illustrated in Fig. 6.a). In this geometrical point the cam has the great radius, resulting in the major torque.

When the torque goes down quickly, it means that cam returns to the base circle and the valve closes. This movement repeats periodically during the engine working.

In the Fig. 13 the torque's curve goes up fast, since the torque depends directly of the cam's curves. The valve reaches its maximum displacement at the time 0.6 sec. allowing the fuel intake in the combustion chamber due to the total opening of the valve. In a detailed analysis of Fig. 13, it is possible to note that in this time the torque is not maximum. A time gap of 0.02 sec. can be noted between maximum torque and maximum displacement of the valve. This fact shows that the maximum torque is reached before the push rod get in contact with the cam's nose, where it is the maximum displacement point. This is a condition that depends on the angular velocity of the cam. This time gap will change for others angular velocities imposed in the camshaft.
The knowledge of the internal forces involved on the mechanical components of the system in the time which corresponds to the maximum torque is very important to an engine designer. The values of these forces may help the designer to determine the required power in order to set motion to the system. With the presented multibody model it is possible to determine all the internal forces (action and reaction forces) involved in the mechanism.

The authors suggest to the reader another interesting study in order to investigate the kinematic and dynamic behavior of the proposed mechanism. These analyses can be conduct in terms of geometrical (dimensions) changes in the rocker arm. The multibody model allows doing these geometrical modification in an easily and fast manner, just modifying the geometrical points table like illustrated in Fig. 6.a. A CAD software can be used too for this geometrical changes, so the data need to be exported to the multibody software in order to replace the referenced table. This kind of study allows determining suitable dimensions in order to save energy and reducing cam's torque.

In the Fig. 14, the linear velocity and acceleration of the valve's center of mass is shown. Analyzing this graph is easily to note that both curves are periodic. As expected in the minimum and maximum velocities' peaks, the acceleration corresponds to a null value, once the acceleration is the first derivative in the time of the velocity. This fact can be observed at $0.5 \mathrm{sec}$. and $0.7 \mathrm{sec}$, respectively. Due to the referential coordinates used (the vertical reference is negative in the up direction) the velocity and acceleration have positive values, when the valve suffers a deceleration.

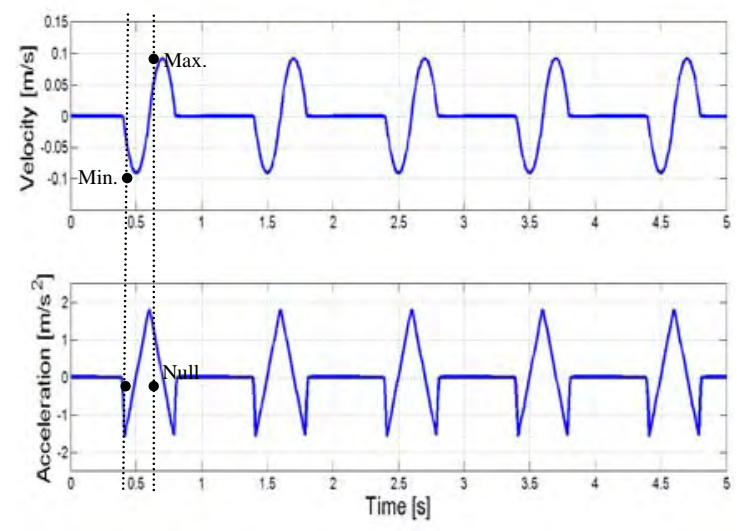

Figure 14. Velocity and acceleration of the valve's center of mass.

The next figures show the results of a sensitivity analysis. The angular velocity imposed to the system (in the camshaft) is changed for each simulation, according to a pre-defined step of $6.28 \mathrm{rad} / \mathrm{s}$. This value corresponds to a complete revolution of the shaft in one second $(360 \%)$. During the simulation time (five seconds), the angular velocity applied in 
the camshaft is constant. Subsequently six simulations were carried out considering the angular velocity varying from $6.28 \mathrm{rad} / \mathrm{s}$ until $37.68 \mathrm{rad} / \mathrm{s}$, following increments of $6.28 \mathrm{rad} / \mathrm{s}$. The results concerning these simulations are the displacement in the valve's center of mass.

Figure 15 to Fig. 17 show three of the six results related to the displacement versus time. The Figure 15 corresponds to an applied angular velocity of 6.28 $\mathrm{rad} / \mathrm{s}$, Fig. 16 corresponds to the next increment of the velocity (12.56 rad/s) and Fig. 17 is the last angular velocity analyzed, which result in a value of $37.68 \mathrm{rad} / \mathrm{s}$.

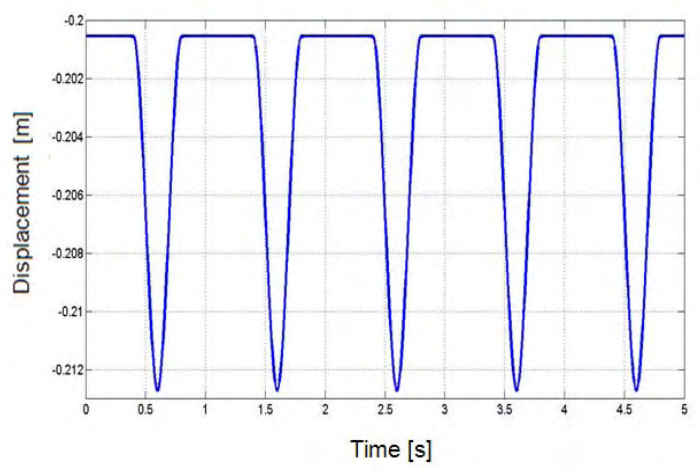

Figure 15. Displacement of the valve with input angular velocity of $6.28 \mathrm{rad} / \mathrm{s}$.

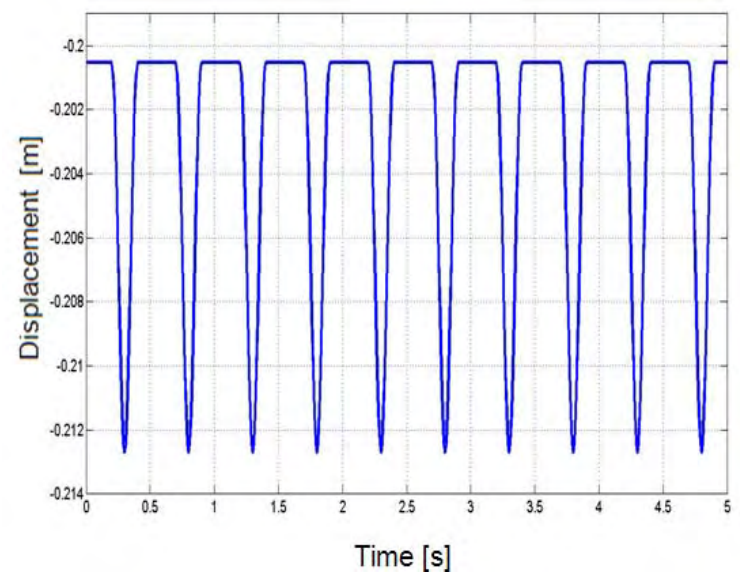

Figure 16. Displacement of the valve with input angular velocity of $12.56 \mathrm{rad} / \mathrm{s}$.

Analyzing the Fig. 15 to Fig. 17, it is possible to note that the system do not react correctly from certain angular velocity imposed in the camshaft, and the results became unsatisfactory, like shown in Fig. 17.

In Fig. 15 and Fig. 16 the displacement amplitude is the same for both simulation and, this amplitude is constant during the simulation time. However the oscillating period changes between them. Although, the Fig. 17 shows that the displacement amplitude varies during the simulation time, which is undesirable for this kind of system.

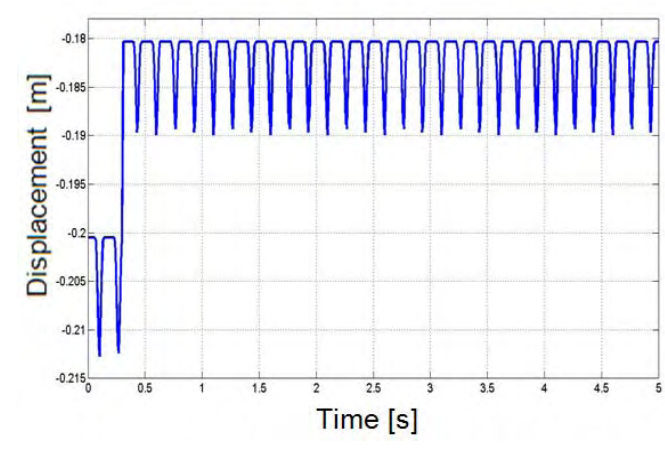

Figure 17. Displacement of the valve with input angular velocity of $37.68 \mathrm{rad} / \mathrm{s}$.

This fact occurs because the spring response time is different in the mechanism operation time. After sensitivity analysis, a refined analysis was done between $25.12 \mathrm{rad} / \mathrm{s}$ ( $4^{\text {th }}$ simulation) to $31.4 \mathrm{rad} / \mathrm{s}$ ( $5^{\text {th }}$ simulation), and it concluded that the maximum velocity without damage to the mechanism is 26.18 $\mathrm{rad} / \mathrm{s}$.

Another important feature of the Adams Software is the Adams/Postprocessor module, which permits the user creates videos of the simulations. Figure 18 illustrates this feature in a media player environment. It is possible to see the motion of the mechanism and its respective point (marker) in the graph.

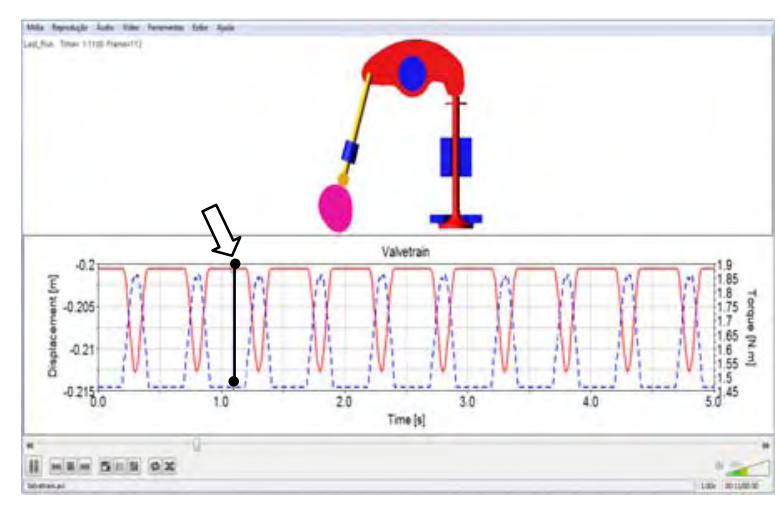

Figure 18. Simulation movie.

The movie presented in Fig. 18 is a great teaching tool, because it is possible to analyze the simulation results (graphs) together with the dynamic motion of the system. This tool is able to increase the understanding of the operating system, improving the understanding of the graphs results and it still increases the interest of the student for learning.

\section{CONCLUSIONS}

This work presents a valvetrain model considering its dynamic and kinematic functioning aspects of Otto's engine. This is a classic mechanism used in automotive and mechanic engineering courses. The model of this mechanism was 
constructed using the multibody software Adams, specifically Adams/View and Adams/Postprocessor modules.

It was shown that this technological tool can help the engineering students to better understand what it happens in terms of displacement, velocity and acceleration of the valve versus time, the force in the spring versus time, and also, the torque in the cam, which are all basic results obtained from this mechanism.

The Adams/View has been proved to be a very suitable tool for teaching this mechanism for students and can be extending to others mechanism. All the simulation results obtained agree with the theory, like illustrated at the classical literature. The complementary tool, the Adams/Postprocessor is effective for the presentation of results including movies.

Therefore, with the union of these two tools (Adams/View and Adams/Postprocessor) an interesting methodology for teaching the kinematic of mechanisms was presented. If the student wishes, new simulations can be performed in real time in the classroom, just by changing parameters of simulations and geometrical parameters, which can be done easily. In this article the focus is not to teach students to use the software but use this tool (the software and their modulus), which is commonly used only in research of specific mechanisms, as a technological aid to stimulate the learning in classrooms and laboratories.

\section{ACKNOWLEDGEMENTS}

The authors would like to thanks FAP-DF (Foundation of Support of Research of the Distrito Federal in Brasil) and UnB-FGA (University of Brasília - Faculty UnB Gama) for the financial support. The authors acknowledge the UnB-Gama College to available the Adams MSC Software for this work.

\section{REFERENCES}

Bosch, 2007, Automotive Handbook, Bentley Publishers, 7th Edition.

Brader, J. S., 2001, Development of a Piezoelectric Controlled Hydraulic Actuator for a Camless Engine, Master Thesis, Department of Mechanical Engineering, College of Engineering and Information Technology - University of South Carolina, EUA.

Gillespie, T. D., 1992, Fundamentals of Vehicle Dynamics, SAE International.

Heisler, H., 2008, Advanced Engine Technology, SAE - Society of Automotive Emgineers, Inc. 